\title{
Depression in females: comparison of patients visiting urban and rural teaching hospitals of Peshawar, Khyber Pakhtunkhwa
}

\section{Submitted}

June 09, 2021

Accepted

June 25, 2021

\section{Author Information}

From: Rehman Medical Institute, Peshawar, Khyber Pakhtunkhwa, Pakistan

Dr. Laiba Shams

House Officer

(Corresponding Author)

Email:

laibashams78@gmail.com

Dr. Musa Kakakhel

House Officer

Dr. Shazma Majeed

House Officer

Dr. Hasnain Khan

House Officer

Dr. Hamza Khan

House Officer

Dr. Sidra Sajid

House Officer

Citation: Shams L, Kakakhel M, Majeed S, Khan H, Khan $\mathrm{H}$, Sajid S. Depression in females: comparison of patients visiting urban and rural teaching hospitals of Peshawar, Khyber

Pakhtunkhwa. J Rehman Med Inst. 2021 Apr-Jun;7(2):16-9.

Laiba Shams, Musa Kakakhel, Shazma Majeed, Hasnain Khan, Hamza Khan, Sidra Sajid

\section{ABSTRACT}

Introduction: Even though frequency of depression is documented globally, the spectrum of depression and its inciting factors in Pakistan are unique to the local cultural and social beliefs.

Objective: To compare the status of depression and its provoking socio-cultural factors among urban and rural females attending selected hospitals of Peshawar.

Materials \& Methods: A cross-sectional comparative study was conducted from March to May 2017 on 93 female patients attending two selected urban and rural teaching hospitals of Peshawar. Data were collected on Beck Depression Inventory through convenience sampling, and were analyzed for descriptive statistics by SPSS version 20. Comparisons were done by the Chi Square test and the Student's $T$ test keeping $\mathrm{p} \leq 0.05$ as significant.

Results: Out of 93 female patients, a final 89 females (53 urban and 36 rural) were included due to incomplete data entries. More urban females were in the normal, mild or borderline clinically depressed categories $(38 / 53,71.7 \%)$, compared to rural females $(15 / 36,41.7 \%)$, more of whom were in moderate, severe and extremely depressed categories $(21 / 36,58.3 \%)$; the difference was significant $(\mathrm{p}=0.025)$. Among the many factors leading to depression, there were significant differences in poor socio-economic status $(\mathrm{p}=0.011)$, illiteracy $(\mathrm{p}=0.003)$ and hostile in-laws ( $\mathrm{p}=0.016$ ), all of which were mainly due to females of rural area rather than urban females.

Conclusion: Rural females suffered significantly greater depression compared to their urban counterparts related to poor socio-economic status, illiteracy, and hostile in-laws.

Keywords: Depression; Anxiety; Stress; Female; Marriage; Domestic Violence.

The authors declared no conflict of interest. All authors contributed substantially to the planning of research, data collection, data analysis, and write-up of the article, and agreed to be accountable for all aspects of the work.

\section{INTRODUCTION}

According to WHO, "Depression is a common mental disorder, characterized by sadness, loss of interest or pleasure, feelings of guilt or low selfworth, disturbed sleep or appetite, feelings of tiredness, and poor concentration". ${ }^{1}$ Depression is a serious condition that has an impact on every aspect of life. Reportedly, one in eight female can suffer from depression at some point throughout her life. ${ }^{2}$ Depression is the leading cause behind illness for females both in high-income and lowmiddle financial gain countries.

Women are more prone to depression than men. A few causes leading to depression in females of Pakistan include marriage and related issues, pregnancy related issues, enduring discrimination, poor social conditions, poor social support, stressful life events, illiteracy, domestic violence, hostile in-laws and lack of an intimate and confiding relationship with the husband. ${ }^{3}$ Depression could be of many types: Major depression, Persistent depressive disorder, Bipolar disorder, Seasonal affective disorder, Psychotic depression, Postpartum depression, Premenstrual Dysphoric Disorder, Situational depression, Atypical depression. ${ }^{4}$

Globally 480 million people are estimated to be suffering from depression. ${ }^{5}$ For depression disorders, women account for $41.9 \%$ cases as compared to $29.3 \%$ among men. ${ }^{6}$ The prevalence of major depression is higher in women than in men; in 2010 its global annual prevalence was $5.5 \%$ and $3.2 \%$, respectively, representing a 1.7 -fold greater incidence in women. ${ }^{7}$ In Pakistan the frequency of depression is higher among females compared to males. According to previous studies, the prevalence of anxiety and depression among women ranges from $30-66 \%{ }^{8}$

Studies conducted in Pakistan have revealed a high prevalence of anxiety and depression on the whole with more than double the prevalence in women, and a higher prevalence in rural compared to urban areas. A survey carried out in Pakistan showed the percentage of women suffering from depression, where $46 \%$ of women were affected in north Pakistan, 66\% in rural Punjab, 25\% in urban Punjab, $57.5 \%$ in urban Karachi and lastly $42.2 \%$ in semi-urban Karachi. ${ }^{9}$ 
Depression varies from person to person and from region to region. This study is based upon a part of the country i.e. Peshawar where women are neglected and their rights are overlooked, more so in the rural areas. As a pilot study, it will highlight the issues that lead to depression in females, so that some of the causes can be addressed through future interventional strategies.

The present study was conducted to compare the status of depression among rural and urban females presenting at two selected teaching hospitals of Peshawar, Khyber Pakhtunkhwa, Pakistan, as well as to determine the provoking factors leading to depression among women selected from the rural and urban areas.

\section{MATERIALS \& METHODS}

A cross-sectional comparative study was conducted from March to May 2017 at Rehman Medical Institute (RMI), Peshawar, an urban teaching hospital and Naseer Teaching Hospital (NTH), Peshawar, a rural hospital, on female patients attending the Outpatients Department using convenience sampling technique. Criteria for inclusion were women from rural and urban areas, willing to participate after informed consent, without any chronic illness, and being Pakistani nationals. Exclusion criteria were women hesitant in providing information or having a language barrier that prevented proper filling out of the questionnaire.

The sample size was calculated by the WHO formula keeping a population prevalence $(\mathrm{p})$ of depression at $68 \%, \alpha$ error at 0.05 , and $\beta$ error at 0.1 ; the calculated sample size was 84 . Data were collected from 93 females on a structured Performa i.e. the standardized Beck Depression Inventory (BDI) that classifies persons into levels of depression based on scores achieved as: These ups and downs are considered normal (scores 1-10); Mild mood disturbance (scores 11-16); Borderline clinical depression (scores 17-20); Moderate depression (scores 21-30); Severe depression (scores 31-40); and Extreme depression (scores over 40).

Verbal and written informed consent was taken from the hospital and the participants. The questionnaire was handed over to the subject provided she was educated. If illiterate, the team member explained it to the subject and assisted them in filling the questionnaire. Data were entered into SPSS version 20; descriptive statistics were calculated, and comparisons done using the Chi Square Test and Student's T Test as applicable, keeping $\mathrm{p} \leq 0.05$ as significant.

\section{RESULTS}

Of the 93 female patients initially selected by convenience sampling, 4 did not mention the area (rural/urban) and were excluded. Of 89 females finally selected, $36(40.45 \%)$ were rural and $53(59.55 \%)$ were urban. Their ages ranged from 17 to 70 years.

Figure 1 compares the status of depression among rural and urban females; there were $38 / 53(71.7 \%$ ) urban females in the normal, mild or borderline clinically depressed categories, compared to $15 / 36(41.7 \%)$ rural females, more of whom were in moderate, severe and extremely depressed categories $(21 / 36,58.3 \%)$ compared to their urban counterparts $(13 / 53,24.5 \%)$.

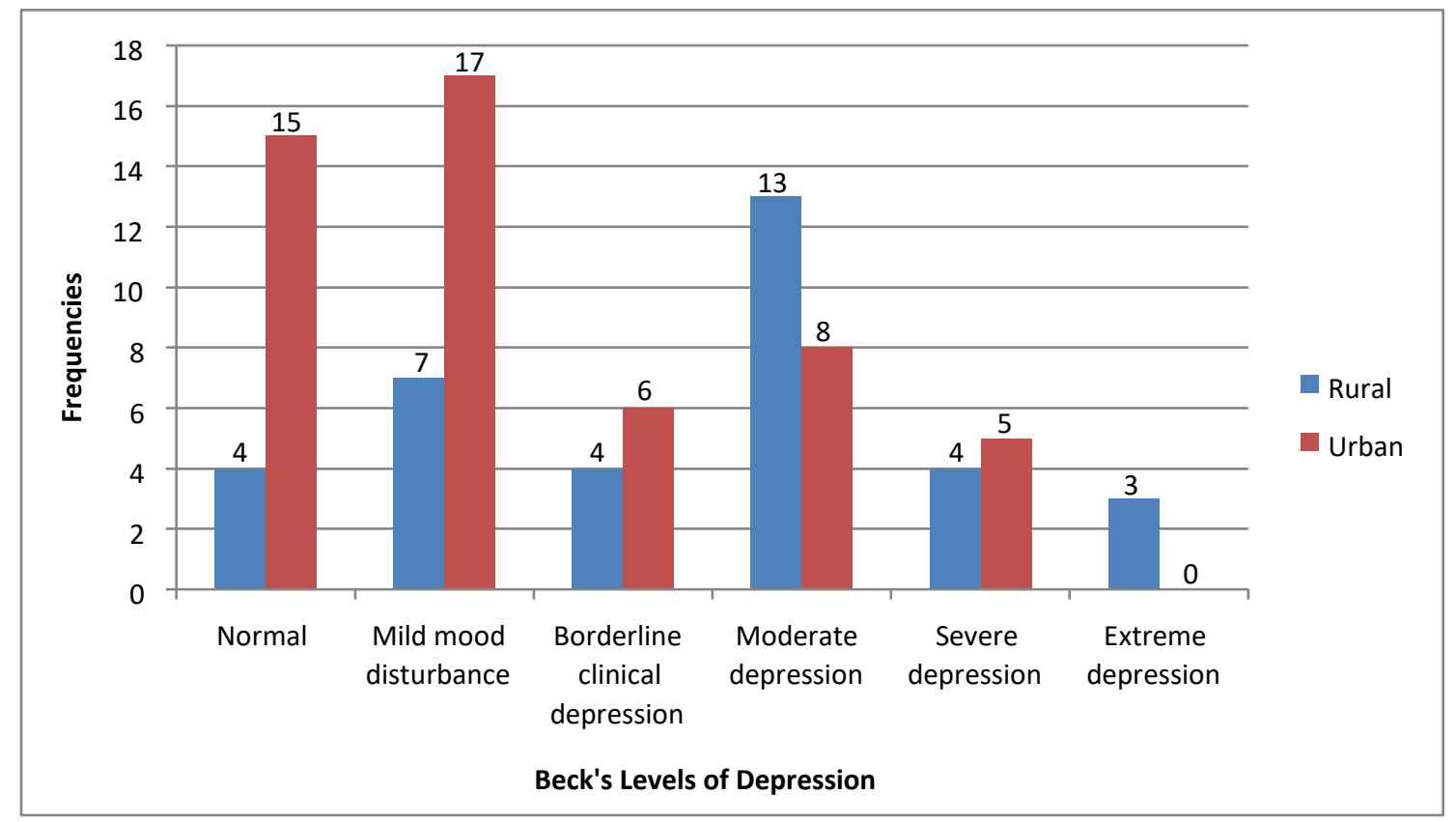

Figure 1: Comparison of the depression status of rural and urban females $(n=89)$.

Table 1 shows the status of depression and provoking factors based on urban or rural area of residence.

Among the many factors leading to depression, there was significant difference in poor socioeconomic status $(\mathrm{p}=0.011)$, illiteracy ( $\mathrm{p}=0.003$ ) and hostile in-laws $(\mathrm{p}=0.016)$. The difference was significant mainly in rural area along with the status of depression, indicating that females from rural area were more depressed than urban females $(\mathrm{p}=0.025)$. 
Regarding the depression categories, there were 11 rural females in the normal and mild categories compared to 32 urban females in these categories; the borderline categories had 04 and 06 females respectively, the moderate category had 13 rural and 08 urban females, the severe category had 05 each, while the extreme category had 03 rural females and no urban females; thus the differences in frequency distributions of the moderate and extreme categories accounted for the significant differences between the rural and urban females in depression categories.

Table 1: Comparison of provoking factors for depression in rural and urban areas $(\mathbf{n}=\mathbf{8 9})$.

\begin{tabular}{|c|c|c|c|c|c|}
\hline$\#$ & Variables & Rural (n=36) & Urban $(n=53)$ & Total $(n=89)$ & $P$ value \\
\hline 1. & $\begin{array}{l}\text { Marriage related issues } \\
\text { Yes } \\
\text { No }\end{array}$ & $\begin{array}{l}08 \\
28\end{array}$ & $\begin{array}{l}08 \\
45\end{array}$ & $\begin{array}{l}16 \\
73\end{array}$ & 0.390 \\
\hline 2. & $\begin{array}{l}\text { Poor socio-economic status } \\
\text { Yes } \\
\text { No }\end{array}$ & $\begin{array}{l}12 \\
24\end{array}$ & $\begin{array}{l}06 \\
47\end{array}$ & $\begin{array}{l}18 \\
71 \\
\end{array}$ & 0.011 \\
\hline 3. & $\begin{array}{l}\text { Pregnancy } \\
\text { Yes } \\
\text { No } \\
\end{array}$ & $\begin{array}{l}06 \\
30 \\
\end{array}$ & $\begin{array}{l}08 \\
45\end{array}$ & $\begin{array}{l}14 \\
75\end{array}$ & 0.842 \\
\hline 4. & $\begin{array}{l}\text { Stress } \\
\text { Yes } \\
\text { No } \\
\end{array}$ & $\begin{array}{l}16 \\
20 \\
\end{array}$ & $\begin{array}{l}17 \\
36 \\
\end{array}$ & $\begin{array}{r}33 \\
56 \\
\end{array}$ & 0.236 \\
\hline 5. & $\begin{array}{l}\text { Illiteracy } \\
\text { Yes } \\
\text { No } \\
\end{array}$ & $\begin{array}{l}09 \\
27\end{array}$ & $\begin{array}{l}02 \\
51\end{array}$ & $\begin{array}{l}11 \\
78\end{array}$ & 0.003 \\
\hline 6. & $\begin{array}{l}\text { Hostile in-laws } \\
\text { Yes } \\
\text { No }\end{array}$ & $\begin{array}{l}07 \\
29\end{array}$ & $\begin{array}{l}02 \\
51\end{array}$ & $\begin{array}{l}09 \\
80\end{array}$ & 0.016 \\
\hline 7. & $\begin{array}{l}\text { Domestic violence } \\
\text { Yes } \\
\text { No }\end{array}$ & $\begin{array}{l}01 \\
35\end{array}$ & $\begin{array}{l}05 \\
48\end{array}$ & $\begin{array}{l}06 \\
83\end{array}$ & 0.219 \\
\hline 8. & $\begin{array}{l}\text { Depression categories } \\
\text { Normal } \\
\text { Mild } \\
\text { Borderline } \\
\text { Moderate } \\
\text { Severe } \\
\text { Extreme }\end{array}$ & $\begin{array}{l}04 \\
07 \\
04 \\
13 \\
05 \\
03\end{array}$ & $\begin{array}{c}15 \\
17 \\
06 \\
08 \\
05 \\
0\end{array}$ & $\begin{array}{l}19 \\
24 \\
10 \\
21 \\
10 \\
03\end{array}$ & 0.025 \\
\hline
\end{tabular}

\section{DISCUSSION}

The aim of this study was to compare the spectrum of depression in females of rural and urban areas and its predisposing factors leading to it. The result of this study is in line with previous studies stating that rural females were more depressed compared to their urban counterparts. ${ }^{9,10}$ The depression in rural females $(58.3 \%)$ was significantly higher than their urban counterparts $(24.5 \%)$.

This study shows that the most significant provoking factor for depression in rural compared to urban women was illiteracy ( $\mathrm{p}=0.003$ ) followed by poor socio-economic status $(\mathrm{p}=0.011)$ and hostile in-laws $(\mathrm{p}=0.016)$; this result is supported in other studies. ${ }^{11}$

Depression is higher in rural females compared to their urban counterparts this could be due to urban females being more educated and have good socio-economic status as comparatively many of them are working which benefits them financially and keeps them occupied. Whereas females in rural areas are mainly dependent on their husbands financially and therefore it affects them in different ways, depression being one of them. Rural females significantly endure more domestic violence, discrimination, hostile in-laws etc. compared to urban females.
This could be because of illiteracy, poverty and that they cannot speak up for themselves and hence end up being mentally disturbed. Rural females struggle with combined effects of poverty disease and social isolation as many of their men folk are employed away from home. ${ }^{11}$ Marriage related issues, stress and pregnancy were other non-significant factors that could lead to a higher depression in rural areas.

Depression is not simply a result of a single factor rather it is a complex disease resulting from a mix of both genetic and environmental factors, thus there could be other differences than what this study shows as genetic factors were not included in this study. There is a need for further studies which should highlight the role of genetic factors and religion contributing to depression and difference in the two selected populations.

\section{LIMITATIONS}

Being a preliminary hospital-based study, the small sample size does not allow generalization.

\section{CONCLUSION}

Rural females suffered significantly greater depression compared to their urban counterparts related to poor socio-economic status, illiteracy, and hostile in-laws. 


\section{REFERENCES}

1. World Health Organization. Depression: definition. [Webpage]. [cited 2021 May 28]. Available from: https://www.euro.who.int/en/healthtopics/noncommunicablediseases/pages/news/news/2012/10/depress ion-in-europe/depression-definition.

2. Noble RE. Depression in women. Metabolism. 2005 May;54(5 Suppl 1):4952. doi: 10.1016/j.metabol.2005.01.014.

3. Batool Z, S Abbasi SR, Zafar MI, Hameed $S$. Evaluation of risk factors and prevalence of depressive disorders among rural females in district Faisalabad. J Anim Pl Sci. 2008 Jan;18(2):89-93.

4. Florida State University. Types of Depression. 08/04/2014 [Internet]. 2002;155(6):2-6. Available from: http://www.webmd.com/depression/guide/ depression-types.
5. Ali BS, Rahbar MH, Naeem S, Tareen AL, Gul A, Samad L, et al. Prevalence of and factors associated with anxiety and depression among women in a lower middle class semi-urban community of Karachi, Pakistan. J Pak Med Assoc. [Internet]. 2008;52(11):513-7.

6. Zahidie A, Jamali T. An overview of the predictors of depression among adult Pakistani women. J Coll Physicians Surg Pakistan. 2013;23(8):574-80.

7. Albert PR. Why is depression more prevalent in women? J Psychiatry Neurosci. 2015 Jul; 40(4): 219-221.doi: 10.1503/jpn.150205.

8. Zainab S, Fatmi Z, Kazi A. Risk factors for depression among married women belonging to higher and lower socioeconomic status in Karachi, Pakistan. J Pak Med Assoc. 2012;62(3):249-53.
9. Deshpande SS, Kalmegh B, Patil PN, Ghate MR, Sarmukaddam S, Paralikar VP. Stresses and disability in depression across gender. Depress Res Treat. 2014;2014 (Article ID 735307):8 pages. [cited 2021 May 30]. Available from: https://doi.org/10.1155/2014/735307.

10. Waqas A, Raza N, Lodhi HW, Muhammad Z, Jamal M, Rehman A. Psychosocial factors of antenatal anxiety and depression in Pakistan: is social support a mediator? PLoS ONE. 2015;10(1): e0116510. doi:10.1371/journal.pone.0116510.

11. Poongothai S, Pradeepa R, Ganesan A, Mohan V. Prevalence of depression in a large urban South Indian population - the Chennai Urban Rural Epidemiology Study (CURES - 70). PLoS One. 2009 Sep 28;4(9):e7185.

doi: 